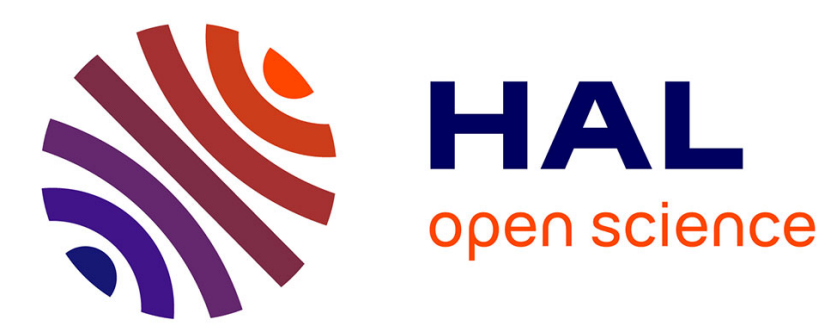

\title{
3. Utilisation de jonctions S-I-M comme thermomètres absolus
}

\author{
W.T. Band, G.B. Donaldson
}

\section{To cite this version:}

W.T. Band, G.B. Donaldson. 3. Utilisation de jonctions S-I-M comme thermomètres absolus. Revue de Physique Appliquée, 1970, 5 (6), pp.900-901. 10.1051/rphysap:0197000506090003 . jpa-00243473

\section{HAL Id: jpa-00243473 https://hal.science/jpa-00243473}

Submitted on 1 Jan 1970

HAL is a multi-disciplinary open access archive for the deposit and dissemination of scientific research documents, whether they are published or not. The documents may come from teaching and research institutions in France or abroad, or from public or private research centers.
L'archive ouverte pluridisciplinaire HAL, est destinée au dépôt et à la diffusion de documents scientifiques de niveau recherche, publiés ou non, émanant des établissements d'enseignement et de recherche français ou étrangers, des laboratoires publics ou privés. 


\title{
3. UTILISATION DE JONCTIONS S-I-M COMME THERMOMẼTRES ABSOLUS
}

\author{
W. T. BAND et G. B. DONALDSON
}

Département de Physique, Université de Lancaster, G. B.

Dans la gamme des températures $T<1 / 4 T_{\mathrm{c}}$ les jonctions tunnel supraconducteur-oxyde-métal normal ont une dépendance du courant en fonction du poten- tiel $(i-V)$ de la forme $i \propto \exp (e V / k T)$ pour une gamme de potentiels appliqués inférieurs à l'énergie de la bande interdite $(2 k T<V<\Delta-1.5 k T)$. Notre 
but est de décrire un système de modulation qui mesure la quantité $i(\mathrm{~d} V / \mathrm{d} i)$ donnant directement la température en fonction de la tension et de la constante fondamentale $k / e$. Les résultats présentés montrent les mesures de température faites dans une gamme de $1{ }^{\circ} \mathrm{K}$ à $2,5^{\circ} \mathrm{K}$ sur des jonctions $\mathrm{Pb}-\mathrm{I}-\mathrm{Al}$ et $\mathrm{Pb}-\mathrm{I}-\mathrm{Mg}$ (les films utilisés sont minces). Ils montrent que le thermomètre est fidèle et exact à $5 \%$. La température mesurée est celle du métal normal. 